\title{
EHMTI-0311. Effect of physical activity and hours of sleep on symptoms scores following migraine
}

\author{
MT Moore ${ }^{1 *}$, Covassin $^{2}$ \\ From 4th European Headache and Migraine Trust International Congress: EHMTIC 2014 \\ Copenhagen, Denmark. 18-21 September 2014
}

\section{Introduction}

Physical activity and regular sleep are a common recommendation by all physicians to mitigate a myriad of disorders. Migraine treatment typically targets reduction of symptoms after onset of the migraine as their primary objective, yet little data exist comparing the symptom scores for medication choices.

\section{Aim}

The purpose of this research is to determine how physical activity status, type of medication and hours of sleep effect the number/intensity of symptoms a migraineur reports.

\section{Methods}

44 migraineurs reported hours of sleep and symptoms scores $0-6$ on a Likert scale $(0=$ no symptoms, $6=\max )$ for 22 symptoms associated with migraine at baseline, 24 hours, 48 hours and 7 days post migraine. Physical activity (meeting CDC minimum criteria) and type of medication [over the counter (OTC), prescription ( $\mathrm{Rx}$ ) OTC + Rx, None] were reported.

\section{Results}

Repeated Measures ANOVA found there was no significant difference between migraineurs in hours of sleep $(\mathrm{p}=.698, \mathrm{~F}=.479)$ or physical activity status $(\mathrm{p}=.822$, $\mathrm{F}=.304$ ) at each measure, but a significant difference in total symptom scores by time $(\mathrm{p}<.001, \mathrm{~F}=18.507)$. Migraineur symptom scores peaked at 24 hours post migraine measurements. A one way ANOVA revealed significant differences between type of medication groups at 24 hours $(\mathrm{p}=.001, \mathrm{~F}=7.210)$ by treatment.

'School of Health and Human Performance, Northern Michigan University, Marquette, USA

Full list of author information is available at the end of the article

\section{Conclusions}

The number of hours of sleep and physical activity status had no effect on the number or intensity of symptoms in migraineurs. It is important to determine outcomes of medications on symptom reduction for each patient to choose the best migraine management strategy.

No conflict of interest.

\section{Authors' details}

${ }^{1}$ School of Health and Human Performance, Northern Michigan University, Marquette, USA. ${ }^{2}$ Kinesiology, Michigan State University, E. Lansing, USA.

Published: 18 September 2014

doi:10.1186/1129-2377-15-S1-D42

Cite this article as: Moore and Covassin: EHMTI-0311. Effect of physical activity and hours of sleep on symptoms scores following migraine. The Journal of Headache and Pain 2014 15(Suppl 1):D42.

\section{SpringerOpen $^{\odot}$}

(C) 2014 Moore and Covassin; licensee Springer. This is an Open Access article distributed under the terms of the Creative Commons Attribution License (http://creativecommons.org/licenses/by/2.0), which permits unrestricted use, distribution, and reproduction in any medium, provided the original work is properly cited.
Submit your manuscript to a SpringerOpen ${ }^{\circ}$ journal and benefit from:

- Convenient online submission

- Rigorous peer review

- Immediate publication on acceptance

- Open access: articles freely available online

- High visibility within the field

- Retaining the copyright to your article 